\title{
Inquietaçoes, decolonialidade e desobediência docente formação inicial de professores/as de artes visuais na América Latina
}

\author{
Inquietudes, decolonialidad y desobediencia \\ docente en la formación inicial de profesores/as \\ de artes visuales en América Latina
}

Eduardo Santos Moura*

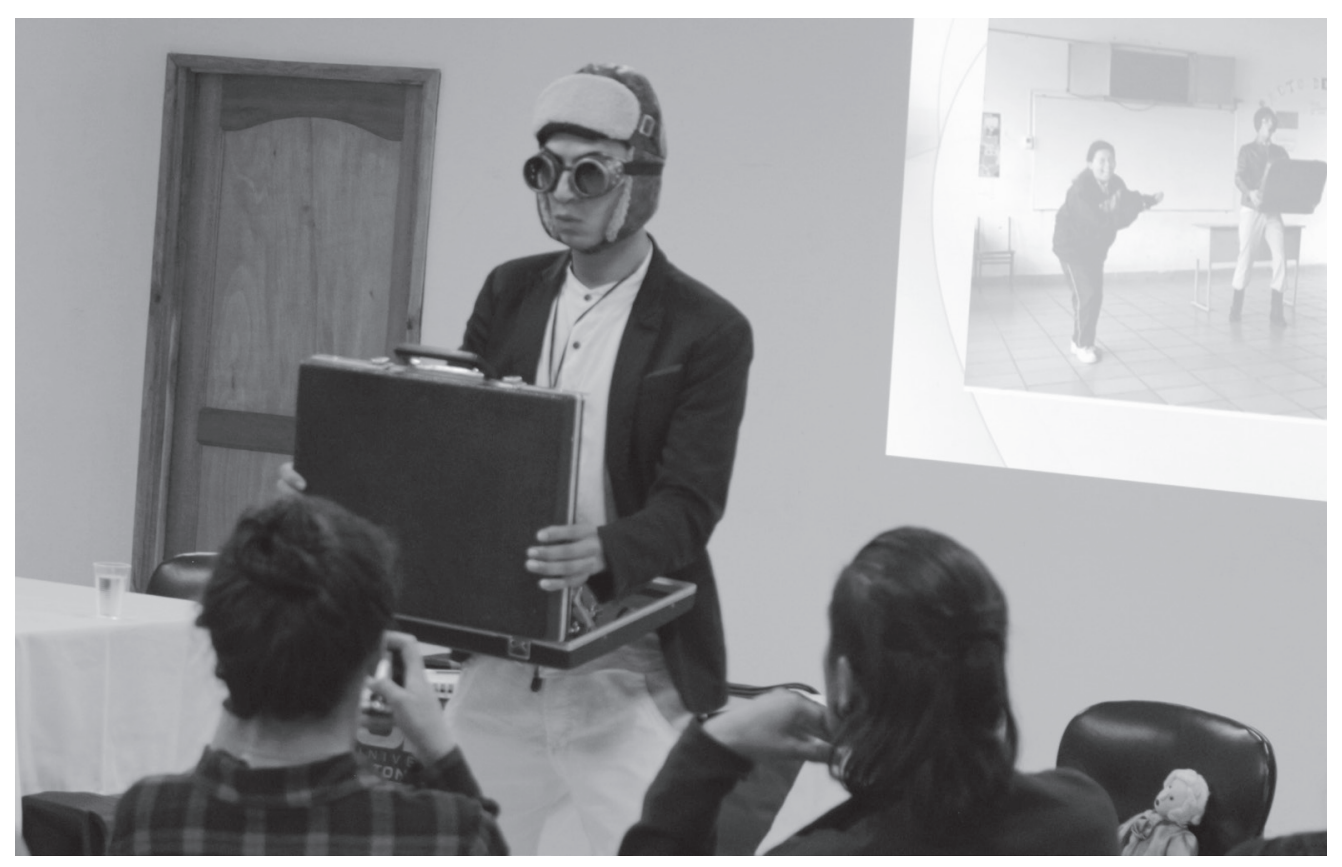

Citar este artículo como: Santos Moura, E. (2017). Inquietaçoes, decolonialidade e desobediência docente formação inicial de professores/as de artes visuais na América Latina. Revista Papeles, 9(18), 21-33.

Fecha de recibido: octubre 1 de 2017.

Fecha de aceptación: diciembre 30 de 2017.

* Doutorando do Programa de Pós-graduação em Educação (Doutorado Latino-americano) da Faculdade de Educação FaE da Universidade Federal de Minas Gerais (UFMG). Mestre em Educação pela Universidade de Brasília (UnB). Professor do Departamento de Artes da Universidade Estadual de Montes Claros (Unimontes), atua no Curso de Licenciatura em Artes Visuais. Doctorando del Programa de Postgrado en Educación (Doctorado Latinoamericano) de la Facultad de Educación FaE de la Universidad Federal de Minas Gerais (UFMG). Maestría en Educación por la Universidad de Brasilia (UnB). Profesor del Departamento de Artes de la Universidad Estatal de Montes Claros (Unimontes), actúa en el Curso de Licenciatura en Artes Visuales. Correo: eduardomourarte@yahoo.com.br 


\section{Resumo}

Apresento algumas inquietações que me movem na investigação da formação inicial de professores/as de Artes Visuais na América Latina hoje. O centro de minhas inquietações está nos processos e ações formativas que constituem os currículos dos cursos de formação inicial docente em Artes Visuais e que legitimam uma matriz de conhecimentos eurocêntrica. Encontro no pensamento do Grupo Modernidade/Colonialidade (Aníbal Quijano, Enrique Dussel, Fernando Coronil, Walter Mignolo, Santiago Castro-Gómez, Arturo Escobar, Catherine Walsh, Zulma Palermo) a perspectiva decolonial para pensar a realidade sócio-histórico-cultural latino-americana. Trato de questionar a hegemonia e a uni-versalidade europeia que hierarquizam, encobrem e invisibilizam outras culturas, expressões visuais e produtores/as de Arte, impossibilitando formas outras de pensar/ produzir a formação inicial de professores/as que, na perspectiva decolonial, passa pela legitimação dos conhecimentos da Arte e da cultura da América Latina. Relaciono o pensamento decolonial latino-americano à Arte, à cultura, à educação e à formação de professores/as de modo a contrapor as grandes narrativas modernistas, e proponho o que chamo de 'desobediência docente' pela decolonialidade dos processos e ações que constituem os currículos dos cursos de formação de Professores/as Artes Visuais na América Latina na perspectiva de produzir ensinos e aprendizagens em Artes Visuais que contribuam para o (re)conhecimento de quem somos como oportunidade de, na coletividade, enfim, deixarmos de ser o que não somos.

Palavras-chave: América Latina; artes Visuais; decolonialidade; desobediência docente; formação inicial de professores.

\section{Resumen}

Presento algunas inquietudes que me mueven entorno a la investigación que adelanto sobre la formación inicial de profesores/as de artes visuales en América Latina hoy. El centro de mis inquietudes está en los procesos y acciones formativas que constituyen los currículos de los cursos de formación inicial de los docentes en artes visuales y que legitiman una matriz de conocimientos eurocéntrica. Encuentro en el grupo de pensadores Modernidad/Colonialidad (Aníbal Quijano, Enrique Dussel, Fernando Coronil, Walter Mignolo, Santiago Castro-Gómez, Arturo Escobar, Catherine Walsh, Zulma Palermo) la perspectiva decolonial para pensar la realidad sociohistóricocultural latinoamericana. Trato de cuestionar la hegemonía y la uni-versalidad europea que jerarquiza, encubre e invisibiliza otras culturas, expresiones visuales y productores/as de arte, imposibilitando otras formas de pensar/producir la formación inicial de profesores/as que, en la perspectiva decolonial, pasan por la legitimación de los conocimientos del arte y de la cultura de América Latina. Relaciono el pensamiento decolonial latinoamericano al arte, a la cultura, a la educación y a la formación de profesores/as para contraponer las grandes narrativas modernistas, y propongo lo que yo llamo "desobediencia docente" por la decolonialidad de los procesos y acciones que constituyen los currículos de los cursos de formación de profesores/as de artes visuales en América Latina en la perspectiva de producir enseñanzas y aprendizajes en artes visuales que contribuyan al (re)conocimiento de quiénes somos como oportunidad de, en la colectividad, en fin, dejar de ser lo que no somos.

Palabras clave: América Latina, artes visuales, decolonialidad, desobediencia docente, formación inicial de profesores. 


\section{Inquietar(-se), questionar(-se), perturbar(-se), incomodar(-se), preocupar(-se), importunar(-se), estranhar(-se), intrigar(-se), atentar(-se), provocar(-se)}

O centro de minhas inquietações está na colonialidade -do poder, do saber e do ser- na América Latina que, refletida na educação, nas universidades, nos cursos de formação docente, nos currículos e nos processos formativos, hegemoniza uma matriz de conhecimentos eurocêntrica e deslegitima os conhecimentos, a Arte e a cultura dessa região.

Inquietam-me a uni-versalidade -uma única versão: europeia -da produção de conhecimentos e as impossibilidades do conhecer desde um olhar geopoético, compreendendo o geo desde o lugar donde me inquieto -América Latina- e o poético desde a dimensão que me inquieta: a Arte. Ambos, lugar e dimensão, pensados pelo campo da Educação. Assim, inquietam-me as questões epistemológicas acerca da Arte na Educação da América Latina. Não se trata de um olhar incauto e desconexo que pensa a Arte da América Latina na Educação; nesse sentido, o que me move é um olhar geopolítico: compreendendo, mais uma vez, o geo desde meu locus de enunciação - América Latina- e o político como dimensão de consciência e de ações com potencial questionador do estabelecido.

Relaciono o inquietar, aqui, com o desassossego próprio e de outrem, assim: inquietar(-se), questionar(-se), perturbar(-se), incomodar(-se), preocupar(-se), importunar(se), estranhar(-se), intrigar(-se), atentar(-se), provocar(-se) (com) as questões artísticas, educacionais, sociais, políticas, culturais e históricas da América Latina.

Busco no pensamento de meu conterrâneo Darcy Ribeiro, em seu livro América Latina: pátria grande (1986), sob a égide da problemática “A América Latina existe?", a justificativa para um olhar regionalista latino-americano. O autor justifica, logo no início da obra, que não há dúvida de que sim, existe uma América
Latina! E prossegue complementando: "mas é sempre bom aprofundar o significado dessa existência" (Ribeiro, 1986, p. 11). Aprofundar o significado da existência da América Latina é conhecer quem sou, e uma oportunidade de, na coletividade, enfim, deixar de ser o que não se é (Quijano, 2005).

Parto dessa forma de pensar e procuro aprofundar o significado da existência contemporânea da América Latina, levantando questões acerca dos campos da Educação e da Arte/educação ${ }^{1 / E d u c a c i o ́ n ~ A r t i ́ s t i c a ~}{ }^{2}$; um passo antes, aponto questionamentos que se relacionam à formação inicial acadêmica de Professores $^{3}$ de Artes Visuais com foco nos processos e ações que constituem o currículo dos cursos de formação docente na perspectiva do pensamento decolonial latino-americano.

Inquietações acerca do ensino/aprendizagem de Arte e da formação docente em Artes Visuais me acompanham desde minha graduação na Licenciatura em Educação Artística (1997-2000), especialmente no que diz respeito à hegemonia europeia das expressões

O termo Arte/Educação começou a ser utilizado no Brasil na década de 1980 com os movimentos de Arte/educadores e intentou desenhar outro panorama para sobrepor a Educação Artística acrítica e apolítica reproduzida no país. O termo não apenas altera uma nomenclatura, mas aponta para transformações nos modos de pensar e fazer o ensino/aprendizagem de Arte no Brasil.

2 O termo Educación Artística é utilizado em países da América Latina para se referir ao ensino de Arte em suas mais variadas expressões - Artes Visuais, Música, Teatro, Dança, Audiovisual - de acordo com as diretrizes político-pedagógicas e educativas em cada país.

3 Utilizarei a designação plural "Professores de Artes Visuais" para referir-me à coletividade desse grupo profissional abrangendo tanto a Professora quanto o Professor desse conteúdo. 
Não posso deixar de debitar à mesma formadora todo o desconhecimento

sobre outras histórias, de outras

Artes e de outros "ismos" silenciados

e socialmente visibilizadores das

realidades latino-americanas:

colonialismo, patriarcalismo,

machismo, racismo, escravismo. e dos/as produtores/as em Artes Visuais que constituíram meus conhecimentos sobre isso em minha formação inicial acadêmica. Destaco aí as marcas deixadas pelas ações de uma professora formadora que ministrou um curso de História da Arte. Seguindo linearmente/ cronologicamente desde uma pré-história europeia com estudos da arte rupestre nas cavernas de Lascaux, na França, e Altamira, na Espanha, até o Modernismo das Artes Visuais na Europa, a professora interrompeu os estudos nesse limiar, pois, para ela, ali atingimos o ápice da Arte que interessava/ precisava ser conhecida no curso. O discurso, marcadamente eurocêntrico dessa formadora não me deixava esquecer do que chamava de "Mãe Grécia" como a divindade que proveu toda a "boa Arte" universal, legando à humanidade o que havia de melhor nesse campo de conhecimento. A Arte que fornecia os conhecimentos, legítimos, de história da Arte para a satisfatória formação de professores de Artes Visuais era proveniente da Europa, na visão eurocêntrica.

Devo a essa formadora todo o conhecimento dos preciosos "ismos" - classicismo, neoclassicismo, romantismo, realismo, impressionismo, expressionismo, simbolismo, fovismo, cubismo, surrealismo, dadaísmo etc. - da história da Arte europeia que construí. Porém, não posso deixar de debitar à mesma formadora todo o desconhecimento sobre outras histórias, de outras Artes e de outros "ismos" silenciados e socialmente visibilizadores das realidades latino-americanas: colonialismo, patriarcalismo, machismo, racismo, escravismo.

Outras inquietações surgiram com a minha inserção na docência em Arte na Educação Básica. A universidade havia me formado para ensinar Arte europeia e estadunidense. Minhas primeiras aulas de Arte, ainda em meio ao processo formativo inicial acadêmico, no ano de 1997, foram ministradas para estudantes da, então, oitava série do Ensino Fundamental, em que deveria dar prosseguimento à sequência didática da professora que substituí. Ironicamente, naquela turma, a sequência didática versava sobre o "Impressionismo" nas Artes Visuais, e a proposta era estudar a vida e a obra de grandes pintores dessa vanguarda pictórica europeia: Claude Monet, Édouard Manet, Vincent Van Gogh, Pierre August Renoir, Edgard Degas e outros pintores - homens, brancos, heterossexuais, europeus.

Ao trazer esses dois exemplos que marcaram meu processo de (de)formação para docência em Artes Visuais, aponto para o que, tristemente, fez/faz parte da constituição dos processos e ações formativas para docência em Arte - não eximindo nenhuma das linguagens que compõe esse conteúdo na Educação Básica: Artes Visuais, Teatro Música, Dança - e persiste, especialmente no que é o foco nessa discussão, nos cursos de formação de Professores de Artes Visuais: ações que privilegiam/legitimam conhecimentos da matriz euro/nortecêntrica do saber e encobrem/ deslegitimam os conhecimentos de matriz latino-americana.

Venho lançando meu olhar sobre o ensino/ aprendizagem das Artes Visuais em contextos de Educação Básica, no Brasil, desde minha formação inicial acadêmica como Professor, passando pela atuação docente em Arte na Educação Básica e, atualmente, como formador de professores em Curso de Graduação Licenciatura em Artes Visuais. A 
partir dessa inserção empírica no campo por quase duas décadas, o que vejo é uma hegemonia europeia e estadunidense nas formas de pensar e produzir o ensino/aprendizagem das Artes Visuais que, a meu ver, pouco ou nenhum sentido/significado fazem para o (re) conhecimento das realidades - artística (em suas diversas expressões), histórica, social, política, cultural - latino-americanas. Desse ponto, permito-me inferir, empiricamente, que há um predomínio nos espaços educativos brasileiros, sejam eles formais, informais ou não-formais, de uma (única) Arte/educação de matriz eurocêntrica/nortecêntrica que opera de forma reprodutivista, acrítica e apolítica, reflexo de uma formação docente na mesma perspectiva.

Considero que há, ainda hoje, uma lacuna de investigações que privilegiem e legitimem a produção de conhecimentos desde as realidades educativas das nações latino-americanas, e uma lacuna maior de investigações que possam contrastar as realidades dos países nessa região de forma a compor um mosaico de conhecimentos que contribuam para a compreensão das aproximações e distanciamentos desses países, considerando suas realidades artísticas, históricas, sociais, políticas e culturais nos contextos circunscritos a essa geo-grafia. Posso afirmar ainda, com base nos levantamentos que venho realizando nos últimos anos, para pesquisa que realizo junto ao Programa de Doutorado Latino-americano em Educação da Faculdade de Educação (FaE) da Universidade Federal de Minas Gerais (UFMG), que há, na literatura, um vazio de estudos que discutam a formação docente em Artes Visuais na América Latina, especialmente na perspectiva decolonial. Contribuindo para minimizar essa lacuna, em meus estudos e pesquisas venho envidando esforços no sentido de questionar o pensar pelo prisma moderno/colonial e apontar as (im)possibilidades de decolonialidade dos processos formativos para docência em Artes Visuais na América Latina.

Interessa juntar-me ao coro que ecoa vozes dos povos latino-americanos rumo à decolonialidade do saber, do ser e do poder. Inquieta-me o desejo e a (im)possibilidade de aclarar os pontos que obscurecem a imagem produzida sobre a América Latina pelo imaginário colonizador europeu. Essa imagem distorcida pelo espelho do colonizador, desde o século XVI, converte-se em verdade universal e contribui com o epistemicídio que cria abjeções, negações, violações, encobrimentos e apagamentos das artes e das culturas latino-americanas.

\section{Colonialismo e colonialidade na América Latina}

O colonialismo ${ }^{4}$ como estrutura de poder, dominação e exploração atingiu pontos

4 Colonialidad es un concepto diferente, aunque vinculado con el concepto de colonialismo. Este último se refiere estrictamente a una estructura de dominación y explotación, donde el control de la autoridad política, de los recursos de producción e del trabajo de una población determinada lo detenta otra de diferente identidad, y cuyas sedes centrales están, además, en otra jurisdicción territorial. Pero no siempre, ni necesariamente, implica relaciones racistas de poder. El colonialismo es, obviamente, más antiguo, en tanto que la colonialidad ha probado ser, en los últimos 500 años, más fulcrais para se estabelecer na América Latina; hoje, pela via da colonialidade como padrão de poder que opera pela naturalização das hierarquias territoriais, raciais, culturais e epistêmicas, possibilita a reprodução das relações de dominação e mantém abertas as feridas coloniais, que seguem profundas, infectadas e sangrando. Utilizo o termo colonialidade - corroborando o pensamento decolonial do

profunda y duradera que el colonialismo (Quijano, 2007, p. 93). 
Grupo Modernidade/Colonialidade ${ }^{5}$ - para referir-me à presença colonial na contemporaneidade; no entender do escritor ganês Kwame Nkruma (1965), trata-se de "neocolonialismo", ou seja, a tentativa moderna de perpetuar o colonialismo.

Para criar um 'não-(re)conhecimento de si' sobre um povo, tire dele sua mais comum e eficaz forma de comunicação: sua língua/seu idioma; retire desse povo as crenças e as idolatrias que povoam seu imaginário e formam suas subjetividades; e crie sobre esse povo representações visuais que ridicularizam, minimizam, uniformizam, inferiorizam e estereotipam. Esses processos caracterizam o colonialismo e sua perpetuação: a colonialidade.

Pensar por esse prisma faz compreender de que maneira a dimensão artística - centrada na produção visual/imagética -, a par das dimensões religiosas (catolicismo) e de linguagem/ idioma (português e espanhol), operou e opera como uma das mais profícuas para implementação e manutenção do projeto moderno/ colonial e da hegemonia euro/nortecêntrica no contexto latino-americano. As imagens do que a América Latina não é e nunca foi são refletidas nos mais diversos campos do conhecimento e, estrategicamente, mantém vivo o colonialismo no campo educacional, hoje como colonialidade.

No que tange, especificamente, à dimensão artística em suas expressões visuais, importa

5 O Grupo Modernidade/Colonialidade é um coletivo de intelectuais latino-americanos que revisam a epistemologia das ciências sociais e humanidades na região. O grupo foi sendo paulatinamente estruturado por vários seminários, diálogos paralelos e publicações. Ainda no ano de 1998, um importante encontro apoiado pela CLACSO e realizado na Universidad Central de Venezuela reuniu pela primeira vez Edgardo Lander, Arthuro Escobar, Walter Mignolo, Enrique Dussel, Anibal Quijano e Fernando Coronil. A partir desse encontro, foi lançada, em 2000, uma das publicações coletivas mais importantes do M/C: La colonialidad del saber: eurocentrismo y ciências sociales (Ballestrin, 2013, p. 97). pensar que as imagens produzidas sobre a América Latina, para a América Latina e, muitas vezes, pelos/as próprios/as latino-americanos/as, são eurocêntricas, ou seja, não são representativas das narrativas reais desse contexto. Desde a invasão das Américas por homens-brancos-heterossexuais-europeus à contemporaneidade, as imagens projetadas desse contexto e sobre esse contexto, por relatos escritos ou visuais, representam os ideais culturais, éticos, estéticos e políticos do colonizador, e compõem a edificação histórica pela lente colonizadora que exclui tudo o que não esteja nos moldes europeus, construindo "um funil no qual só passarão aquelas pessoas cujo perfil se ajuste ao tipo requerido pelo projeto da modernidade: homem, branco, pai de família, católico, proprietário, letrado e heterossexual", como aponta o filósofo colombiano Santiago Castro-Gomez (2005, p. 81).

Desde os relatos de Américo Vespúcio e Cristóvão Colombo, nos séculos XV e XVI, em que pesem as diferenças culturais e o espanto com os povos do Novo Mundo e seus costumes, foram criadas imagens de seres bárbaros e descivilizados que justificaria os processos de modernização a que seriam submetidos os povos das Américas. Nos relatos dos muitos viajantes que por aqui passaram, os gentios dessas terras foram caracterizados sempre pela falta. Assim, encadeia-se um relacionamento, tanto dos povos americanos, quanto de uma visão uni-versal ${ }^{6}$ do Velho Mundo, com imagens produzidas em vínculos de decadência, desumanidade e monstruosidade as quais refletem o que o colonizador quer mostrar, pois são produzidas pela episteme hegemônica e, até hoje, reproduzem processos excludentes via capitalismo contemporâneo, globalização, promessas de modernidade/civilização.

A composição imagética da América Latina difundida e presente nos centros de produção de conhecimento acadêmico e nos espaços

6 Utilizo "uni-versal" para referir-me à ideia de versão única dos fatos históricos: europeia. 


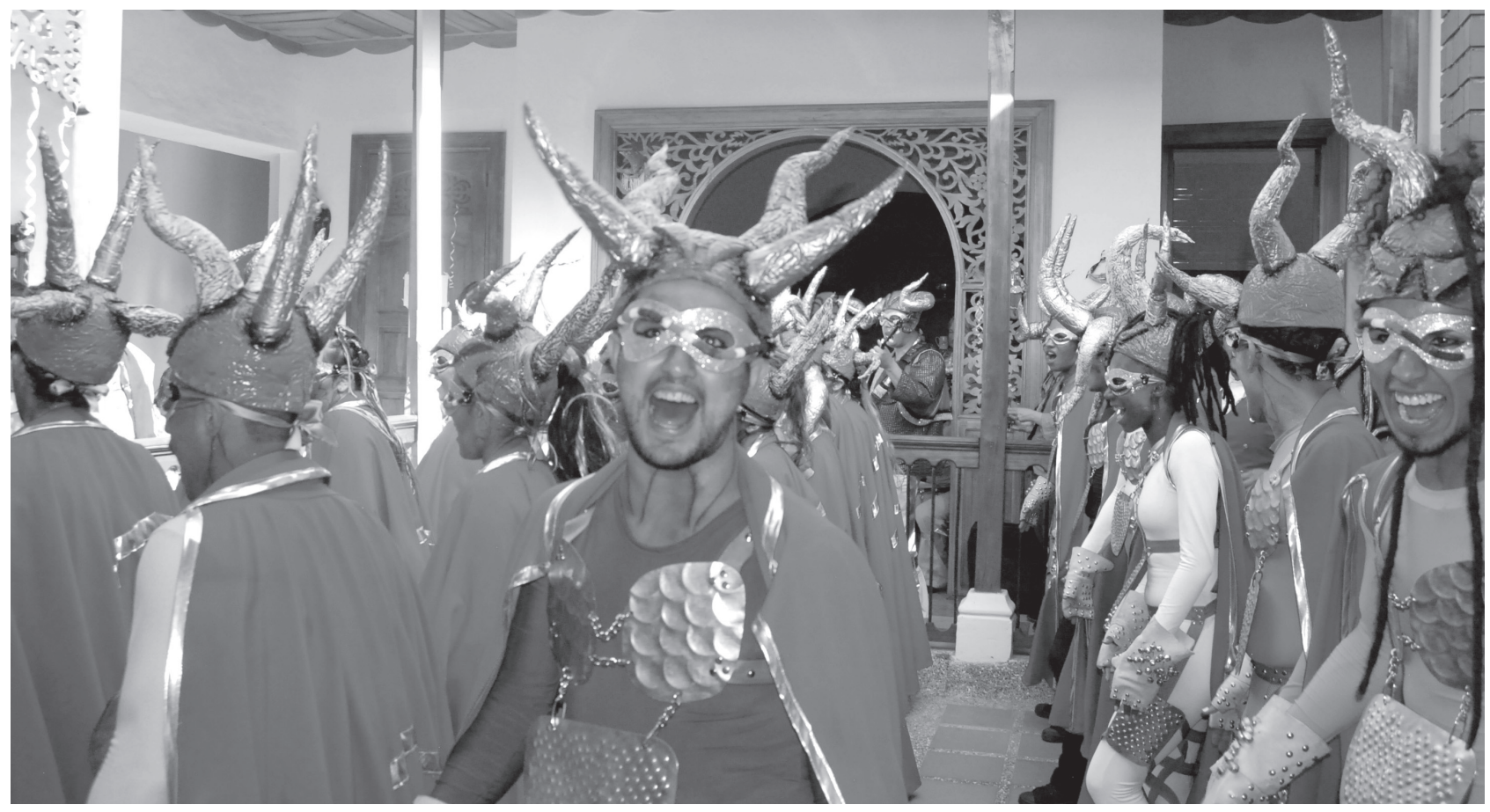

educativos, esquematizada desde os primeiros relatos escritos como os de Colombo, Caminha e Vespúcio - criadores do imaginário estereotipado sobre essa América -, se colocada diante de um espelho, só permite ao colonizador se ver e se reconhecer. Nesse sentido, somos uma sociedade que reflete a imagem colonial. Ao colonizado resta a aquiescência do que parece ser, numa visão incauta, a descrição das novas culturas descobertas - ou encobertas - ou um registro imagético documental ou, ainda, uma expressão artística sobre o Novo Mundo.

Há uma construção nos livros e em suas histórias - como primeiras formas de registro dos invasores - e até em exposições museais e espaços de arquivo/documentação hoje que contribui para perpetuar as heranças coloniais, representadas com força pela imagem, que impregnaram os olhares e deram a atrocidades como a escravização de índios e de negros por toda a América Latina aparência natural ou necessária à civilização/modernização. $\mathrm{O}$ poder da imagem de fixar nas mentes as ideias e os ideais europeus foi explorado com grande competência pelo velho mundo, de forma que até hoje os referenciais, seja de bom ou de belo, nos remetem ao que é externo e nem sempre ao que é próprio.

Aproximando tal visada ao campo da Educação, desde essa genealogia das imagens sobre os povos americanos até a gama de produções imagéticas da/na América Latina, vejo-o como locus privilegiado de reprodução dos ideais opressores do colonizador, espaço onde ganham legitimidade, que sustenta e mantém a colonialidade viva. Direciono meu olhar para espaços escolares no contexto brasileiro - sem pretensões generalistas a toda a América Latina - e vejo que, por meio de Professores de Artes Visuais, das aulas de Artes Visuais - especialmente nas últimas décadas com a inserção desse conteúdo nos currículos escolares -, erigiu-se uma cegueira em relação às expressões, aos/ às produtores/as e à produção artística latino-americana - não exclusivamente visual -, e uma consequente ausência destes/as entre os conteúdos estudados nas escolas, nas aulas de Arte. Isso contribuiu para o desconhecimento da cultura, das expressões artísticas/ 
visuais latino-americanas como representações identitárias, mestiças, dos povos das Américas, a partir das heranças indígenas, indo-americanas e afro-americanas, sendo estas suplantadas pelos olhares, as artes e culturas europeia e estadunidense.

A episteme eurocêntrica, única e excludente, já na constituição das primeiras universidades latino-americanas e na (con)formação docente em muitas instituições até a contemporaneidade, homogeneíza as formas de produzir conhecimento e de conhecer, de tal forma que a única versão de Arte ensinada e aprendida nos espaços educativos é europeia. As imagens que compõem o repertório, o imaginário e o saber docente são europeias.

O desafio de pensar o ensino/aprendizagem de Arte na contemporaneidade na perspectiva decolonial está em constituir, de início na escola, como primeiro espaço democrático de produção do conhecimento, e se expandindo por todas as dimensões e espaços educativos, epistemes outras e, pela via antropofágica, deglutir o que não reflete a imagem do que é a América Latina e seus povos, na busca da imagem do que sempre foram.

\section{Decolonialidade no pensamento latino-americano contemporâneo}

As feridas abertas pelo pensamento eurocentrado, excludente e hegemônico, estão vivas no pensamento latino-americano. Na América Latina o pensar social, cultural, político, histórico, filosófico, antropológico etc. passa pela Europa. E antes de existir Europa, como pensavam os povos autóctones? Era possível pensar? São possíveis, hoje, outras formas de pensar o mundo? É possível pensar o mundo desde a América Latina?

Encontrei no Grupo Modernidade/Colonialidade um dos caminhos teóricos para aprofundar o significado da existência da América Latina. O programa de estudos do Grupo M/C pode ser compreendido como uma forma de pensar que contrapõe as grandes narrativas modernistas, ao localizar seus questionamentos nas bordas dos sistemas de pensamento e investigações, possibilitando modos de pensamento não-eurocêntrico (Escobar, 2003). O pensamento compartilhado por esse grupo é a coexistência de diferentes epistemes e formas de produção de conhecimento que coloca em xeque o desenho colonial e imperial da geopolítica do conhecimento e a subalternização epistemológica que esse modelo promove (Walsh, 2008).

O pensar decolonial nos processos de produção de conhecimentos trata de romper com os uni-versalismos alienantes e coloca em pauta, pela análise crítica, os binarismos modernos que inundam as academias: norte/ sul, ocidente/oriente, colonizador/colonizado, rico/pobre, cultura/natureza, branco/negro, homem/mulher, ciência/arte. Por outras vias, trata de pensar co-existências - de mundos, de conhecimentos, de lugares, de povos, de ciências, de artes, de culturas, de pensamentos - problematizando as hierarquias, legitimando processos anti-hegemônicos, imaginando entrelugares e formas outras de produção de conhecimentos.

Para o pensador argentino Walter Mignolo (2007), não se trata de deslegitimar, mas ultrapassar os limites das teorias euro/nortecentradas (marxismo, freudismo, lacanianismo, foucaultianismo, Escola de Frankfurt etc.) e legitimar outras teorias. O sentido decolonial implica pensar a partir das categorias de pensamento não incluídas nos fundamentos do pensamento ocidental (Mignolo, 2007). Implica legitimar formas de pensar e conhecer gestadas apesar dos silenciamentos/apagamentos teóricos e da hierarquização que inferioriza pensadores e pensadoras de outros contextos, especialmente da América Latina, como Paulo Freire, Frantz Fanon, Aimé Cèsaire, Darcy Ribeiro, Conceição Evaristo, Édouard 
Glissant, dentre tantos outros e tantas outras, valorizando coletivos que pensam pelo viés decolonial.

Pensar formas diversas de produzir conhecimento implica reconhecer que o colonialismo legou aos povos colonizados uma dominação epistemológica que produziu relações desiguais de saber/poder em que o resultado foi a hegemonia de uma forma de saber opressora das formas próprias dos povos colonizados, relegando muitos outros saberes à subalternidade (Santos, 2009). O desafio está em ultrapassar a epistemologia moderna em favor do que Santos (2009) chama de "paradigma emergente" ou dos chamados saberes do sul/ sur (Miglievich-Ribeiro, 2014).

No pensar pela via decolonial, Mignolo (2007, p. 290) aponta que "Pensamento descolonial significa também o fazer descolonial, já que a distinção moderna entre teoria e prática não se aplica quando você entra no campo do pensamento da fronteira". O pensador argentino, a partir do conceito de colonialidade do poder implicado nas teorias e no pensamento do sociólogo peruano Aníbal Quijano sobre a América Latina, explora distintas dimensões da colonialidade. A ideia de Mignolo (2004) é que, colada à colonialidade do poder, também existe a colonialidade do saber e também uma colonialidade específica do ser. Nessa direção, Mignolo (2004; 2014) aponta que a colonialidade opera em três níveis: Colonialidade do poder: político e econômico; Colonialidade do saber: epistêmico, filosófico, científico; Colonialidade do ser: subjetividade, sexualidade, raça, gênero.

A ideia de Europa como centro do poder, centro do saber e ser ideal - homem, branco, heterossexual, letrado, pai de família, proprietário (Castro-Gómez, 2005) - foi proficuamente criada que parece se converter em religião no culto à 'deusa' Europa.

Interrogamo-nos hoje por que razão esta crença se conseguiu entranhar tão forte não apenas no público em geral, mas entre todos
Vejo e compreendo que o problema para o europeu reside no outro e, nesse sentido, tudo que está no outro, que venha do outro - considerado bárbaro, iletrado, despadronizado, cópia imperfeita, não-humano, desalmado, descivilizado - não pode ser legítimo, é inferior.

os tipos de cientistas, filósofos analíticos e estudantes, em que estas crenças são incutidas da mesma forma que a igreja incute as suas próprias crenças nos seguidores (Mignolo, 2004, p. 677).

A forma - única - de pensar, eurocêntrica (pautada na racionalidade científica), converteu-se numa visão universal, mas não universal no sentido em que abrangeria o conhecimento de todo o universo, mas no sentido em que coloca a Europa como o próprio universo, e tudo que dali emana se converte em verdade; nesse sentido, numa única versão de todas as coisas: uni-versal. Visão segundo a qual o europeu (homem) é a base epistemológica de todo conhecimento construído/ a construir, e qualquer outra forma de pensar e produzir conhecimento está na periferia, não existe, não importa/interessa.

O filósofo argentino Enrique Dussel me ajuda a compreender o emaranhado de relações tecidas quando penso em como se operou a (re)produção da visão de superioridade/ legitimidade do pensamento europeu e a inferiorização/deslegitimação construída por essa mesma visão sobre todas as outras formas de pensar que não provenham dessa matriz. Para Dussel (2005, p.27), "Esta Europa Moderna, desde 1492, 'centro' da História Mundial, constitui, pela primeira vez na história, a todas as outras culturas como sua 'periferia"' O autor apresenta o que chama de "estrutura centro -periferia do sistema mundial", em que todas as 
'outras' culturas 'periféricas' - América Latina, América do Norte, Mundo Muçulmano, África banto, Sul da Ásia, China - derivam de uma cultura central que é a Europa Moderna (Dussel, 2005).

Vejo e compreendo que o problema para o europeu reside no outro e, nesse sentido, tudo que está no outro, que venha do outro - considerado bárbaro, iletrado, despadronizado, cópia imperfeita, não-humano, desalmado, descivilizado - não pode ser legítimo, é inferior. Isso move meu desejo de virar o espelho e refletir para o europeu que o problema não reside no outro, reside na visão que ele tem do outro, ou seja, o problema está no Eu do europeu: reside na visão de que a Europa é o centro do mundo e do poder, legitimado pelo capitalismo.

Compreender a relação estabelecida pelo europeu com o outro me faz (res)sentir as feridas abertas pelo colonialismo na América Latina. Em que pesem os contextos históricos de análise aqui implicados, considero essas feridas ainda abertas pela colonialidade na medida em que as alteridades dos povos da América foram desconsideradas em nome de 'um deus', objetivo primeiro do projeto moderno/colonial europeu.

\section{Desobediência docente como perspectiva decolonial dos processos formativos de Professores/as de Artes Visuais}

Ô meu corpo, faça sempre de mim um homem que questiona!

Frantz Fanon

Quando penso os apagamentos e as invisibilizações das expressões artísticas latino-americanas entre os conteúdos das aulas de Artes Visuais, e mesmo de outras disciplinas, nas escolas de educação básica, e o desconhecimento - na melhor das hipóteses - ou os encobrimentos dessas expressões por parte dos/as formadores/as, dos currículos dos cursos de formação e dos/as professores/as da disciplina Artes Visuais, inicio um refazimento dos trajetos que produziram tais silenciamentos. Nesse percurso, caminho por territórios de conhecimento que a modernidade eurocêntrica fragmentou - arte, história, antropologia, sociologia, filosofia -, e que na epistemologia do pensamento latino-americano se fundem na busca por dar contornos, despretensiosos, a um panorama das heranças coloniais legadas como colonialidade do poder, do ser e do saber.

$\mathrm{Na}$ dimensão sócio-cultural: Como se reconhecer latino-americano/a ou latino imerso/a em um universo de conhecimentos
- imagético, artístico, cultural - no qual tudo remete à Europa? Na dimensão educacional: Qual o sentido de formar professores de Artes Visuais na América Latina com referenciais de Arte e cultura que têm como base uma matriz europeia de conhecimentos? Qual o sentido de um ensino/aprendizagem de Artes Visuais eurocêntrica na América Latina?

A centralidade destas inquietações está no eurocentrismo não como espaço ou localização geográfica, mas como forma de pensar que se impõe única, verdadeira e universal. Nessa perspectiva, dado o eurocentrismo nas universidades, nos currículos dos cursos de formação docente, temos na América Latina não somente uma (única) formação docente em Artes Visuais, como também uma (única) forma de educar: eurocêntrica. Fruto de uma forma de pensar reprodutivista, acrítica e apolítica, essa ideia de Europa como o centro do mundo deslegitima outras formas de pensar e corrobora o projeto moderno/colonial, que produziu as imagens, artes e culturas das 
Américas e de seus povos de modo que só o colonizador aí se reconhece.

O discurso falacioso homogeneizante de que não há hoje como se reconhecer pertencente a um lugar (desterritorialização) face à globalização é mais uma estratégia modernista europeia que cria a ideia de 'cidadão do mundo': aquele que é do mundo e, ao mesmo tempo, pertence a lugar nenhum. A ideia do não-lugar cria a falsa ilusão de que não é preciso se identificar com nenhuma cultura específica, pois o mundo é o seu lugar. Diga isso ao europeu, diga-lhe que não há motivo para se identificar a uma cultura francesa, italiana, alemã, portuguesa, espanhola, pois o mundo é o seu lugar. Como observou Darcy Ribeiro, "Ser europeu, disse Sartre uma vez, era de fato a única forma natural, normal e desejável de ser gente. Aos outros faltava alguma coisa essencial que os fazia irremediavelmente carentes. E não bastava ser europeu, era preciso ser francês ou inglês" (1986, p. 112). A globalização a serviço do sistema-mundo capitalista, tendo a Europa como centro do poder, encobre outras culturas, mas mantém viva a Europa como divindade donde provém o conhecimento e a cultura universalizantes. Esse é o discurso por trás da globalização que se mostra homogeneizadora quando se trata da cultura do outro, mas mantém heterogêna e inabalável a cultura europeia. Não existe globalização que legitime epistemes latino-americanas, africanas, asiáticas ou mesmo que evidencie essas culturas em cenários globais.

$\mathrm{Na}$ contramão da hegemonia eurocêntrica nas formas de produzir a formação docente em contextos latino-americanos, proponho a desobediência docente nos processos de formação inicial acadêmica de Professores/as de Artes Visuais. Implica pensar a perspectiva decolonial como forma de superação das hierarquizações que legitimam uma epistemologia eurocêntrica e deslegitimam uma educação - e uma arte/educação - baseada nos conhecimentos desde as artes, as culturas e as imagens latino-americanas. Compreendo

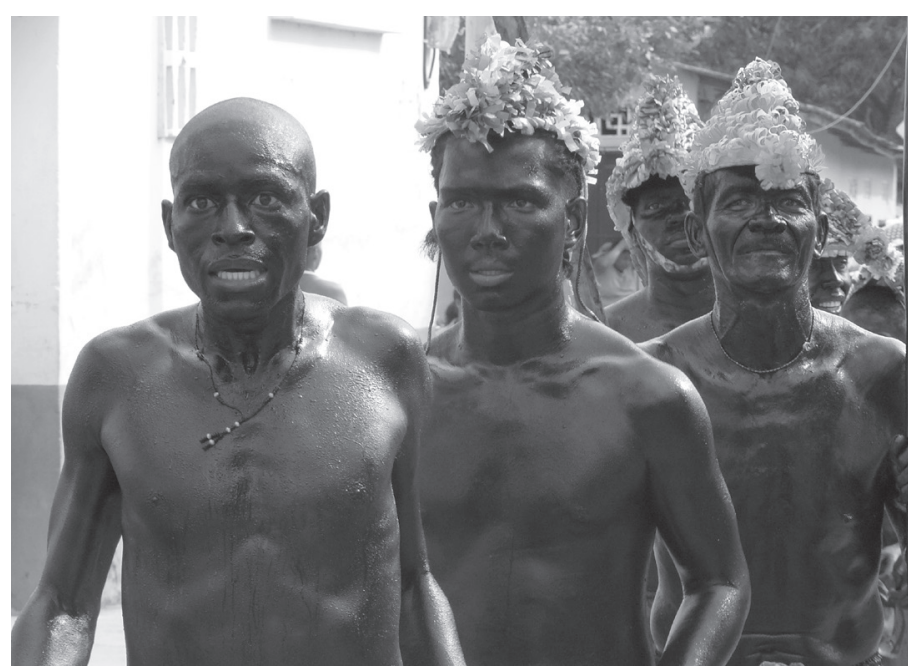

que somente a partir do (re)conhecimento e da identificação com a América Latina, com a história colonial e com as tristes heranças legadas pelo racismo, escravismo, violência, patriarcado, machismo, capitalismo e modernidade/colonialidade, desvelados pelas imagens do que realmente somos, é que será possível decolonizar as formas de pensar, conhecer, sentir a América Latina, viver nela.

A desobediência docente de que trato não se limita a conhecer Arte latino-americana ou inserir no currículo dos cursos de formação inicial docente em Artes Visuais disciplinas ou conteúdos de Arte latino-americana; vai além: reclama uma desobediência docente que só fará sentido se for epistemológica, implica aprender a desaprender para reaprender (Mignolo, 2008). Nessa direção, demarca e dá contornos à produção de conhecimentos em Artes Visuais, desde a formação inicial dos professores até os processos educativos elementares formais ou não-formais que legitimam outras epistemes, não-eurocêntricas, criam identificação com a América Latina na dimensão cultural, reconhecem a história colonial e ampliam o espectro para uma consciência decolonizada.

Há que se pensar a desobediência docente como uma construção cujo alicerce sejam professores de Artes Visuais como sujeitos 


\section{Compreendo que somente a partir do (re)conhecimento e da identificação com a América Latina, com a história colonial e com as tristes heranças legadas pelo racismo, escravismo, violência, patriarcado, machismo, capitalismo e modernidade/colonialidade, desvelados pelas imagens do que realmente somos, é que será possível decolonizar as formas de pensar, conhecer, sentir a América Latina, viver nela.}

- não exclusivamente - capazes de imprimir as marcas de um projeto decolonizador das formas de pensar/conhecer Artes Visuais, em que os olhares se voltem também para o território e as realidades latino-americanas, como forma de conhecer, reconhecer e problematizar a nossa produção artística/ poética, ao invés de legitimarmos uma única história: ocidental - Europa/EUA. Implica pensar as potencialidades artísticas das expressões visuais da América Latina por produtores desse/nesse contexto, as quais, levadas ao campo da Educação em Artes Visuais, contribuam para a legitimação das visualidades latino-americanas.

Ao fazer referências ao pensamento do sociólogo peruano Aníbal Quijano, quando aponta que é tempo, enfim, de deixar de ser o que não somos, proponho construir, desde o campo da Educação, pela desobediência docente em Artes Visuais, as imagens do que sempre fomos, mas que nos foi negado ser. É uma oportunidade de (re)conhecermo-nos latino-americanos/as!

\section{Referências}

Ballestrin, L. (2005). América Latina e o giro decolonial. Revista Brasileira de Ciência Política, nº11. Brasília, maio - agosto de 2013, pp. 89-117.

Castro-Gómez, S. (2005). Ciências sociais, violência epistêmica e o problema da invenção do outro. In: LANDER, Edgardo (Org.). A colonialidade do saber: eurocentrismo e ciências sociais. Perspectivas latinoamericanas. Colección Sur Sur, CLACSO, Ciudad Autónoma de Buenos Aires, Argentina, pp. 80-87

Dussel, E. (2005). Europa, Modernidade e Eurocentrismo. In: LANDER, Edgardo (Org.). Colonialidade do saber: eurocentrismo e ciências sociais. Perspectivas latino-americanas.

Escobar, A. (2003). Mundos y conocimientos de otro modo: el programa de investigación modernidad/colonialidad latinoamericano. Tabula Rasa, n. 1, pp. 58-86 jan-dez.
Fanon, F. (2008). Pele negra, máscaras brancas. Salvador: EDUFBA.

Miglevich-Ribeiro, A. (2014). Por uma razão decolonial: Desafios ético-político-epistemológicos àcosmovisão moderna. Civitas, Porto Alegre, v. 14, n. 1, pp. 66-80, jan.-abr. (Dossiê Diálogos do Sul)

Mignolo, W. (2004). Os esplendores e as misérias da 'ciência': colonialidade, geopolítica do conhecimento e pluri-versalidade epistêmica. In: Santos, Boaventura de Sousa (Org.). Conhecimento prudente para uma vida decente: um discurso sobre as ciências revisitado. São Paulo: Cortez, pp. 667-710

Mignolo, W. (2007). La idea de América Latina. La herida colonial y la opción decolonial. Barcelona: Gedisa, 2007.

Mignolo, W. (2007). El pensamiento decolonial: desprendimento y apertura. Un manifiesto. 
In: Castro-Gómez, Santiago \& Grosfoguel, Ramon (coords.). El giro decolonial: reflexiones para una diversidad epistêmica más allá del capitalismo global. Bogota: Siglo del Hombre Editores; Universidad Central, Instituto de Estudios Sociales Contemporáneos, Pontificia Universidad Javeriana, Instituto Pensar, pp. 25-46

Mignolo, W. (2008). Desobediência epistêmica: a opção descolonial e o significado de identidade em política. Cadernos de Letras da UFF - Dossiê: Literatura, língua e identidade, n. 34, pp. 287-324.

Mignolo, W. (Comp) (2014). Capitalismo y geopolítica del conocimiento. El eurocentrismo y la filosofia de la liberación en el debate intelectual contemporáneo. Ciudad Autónoma de Buenos Aires: Del Signo.

Nkrumah, K. Neocolonialism: the last stage of imperialism. London: Thomas Nelson \& Sons Ltd., 1965. Disponível em: https://www. marxists.org/subject/africa/nkrumah/neocolonialism/index.htm

Quijano, A. (2005). Colonialidade do Poder, Eurocentrismo e América Latina. In: LANDER, Edgardo (org). A colonialidade do saber: eurocentrismo e ciências sociais. Perspectivas latinoamericanas. Colección Sur Sur. Ciudad Autónoma de Buenos Aires, Argentina: CLACSO, 2005.

Quijano, A. (2007). Colonialidad del poder y clasificación social. In: Castro-Gómez, Santiago \& Grosfoguel, Ramon (coords.). El giro decolonial: reflexiones para una diversidad epistêmica más allá del capitalismo global. Bogota: Siglo del Hombre Editores; Universidad Central, Instituto de Estudios Sociales Contemporáneos, Pontificia Universidad Javeriana, Instituto Pensar, pp. 93-126

Ribeiro, D. (1986). América Latina: pátria grande. Porto Alegre: Guanabara.

Ribeiro, D. (2010). A América Latina existe? Rio de Janeiro: Fundação Darcy Ribeiro; Brasília, DF: Editora UnB, 2010. (Coleção Darcy no bolso, v.1.)

Santos, B. (2009). Una epistemología del sur. México, Siglo XXI: CLACSO.

Walsh, C. (2008). Interculturalidad, plurinacionalidad y decolonialidad: las insurgencias político-epistémicas de refundar el Estado. Tabula Rasa. Bogotá - Colômbia, No.9: 131152, julio-diciembre. 